\title{
MATERIAIS DIDÁTICOS PARA A EDUCAÇÃO DE JOVENS E ADULTOS*
}

\author{
OSMAR FÁVERo
}

\begin{abstract}
RESUMO: Após breve retrospecto de trabalho anterior sobre o tema e algumas informações sobre a produção dos materiais didáticos para educação de jovens e adultos elaborados nos anos de 1980, apresenta essa produção nos anos de 1990, a saber: o programa político-pedagógico da Central Única dos Trabalhadores (cut) e o material didático por ela elaborado para os programas Integrar e Integração; a proposta pedagógica do Movimento dos Trabalhadores Sem-Terra e os materiais utilizados nos seus acampamentos e assentamentos: o conceito de totalidades do conhecimento dos livros Palavras de trabalhador, editados pelo Sistema de Educação de Jovens e Adultos (seja), da Prefeitura Municipal de Porto Alegre, produtos da experiência educativa realizada com jovens e adultos trabalhadores. Conclui explorando os pontos comuns ao material didático apresentado.
\end{abstract}

Palavras-chave: Educação de jovens e adultos. Material didático.

\section{TEACHING MATERIALS FOR ADULT AND YOUTH EDUCATION}

ABSTRACT: After a brief review of the literature on the theme and some information on the production of teaching material for adult and youth education elaborated in the 1980's, this article presents different materials produced in the 1990s as the political-pedagogical program of the Workers' Central Organization (CUT); and the teaching materials it produced for the Integrar (To Integrate) and

* Uma versão preliminar desse texto foi apresentada no Grupo de Trabalho "Educação de Pessoas Jovens e Adultas", durante a 27a Reunião Anual da ANPEd, em novembro de 2004. Para sua elaboração foi valiosa a cooperação de Maria Clara Di Pierro e Francisco Lopes, ambos da Ação Educativa, assim como o ajuda de Nilton Fischer e Sonia Rummert, aos quais agradeço vivamente. Na versão atual, mantive o tom oral da comunicação.

** Doutor em Educação pela Pontifícia Universidade Católica de São Paulo (PUC/SP) e professor do Programa de Pós-Graduação em Educação da Universidade Federal Fluminense (UfF). E-mail:ofavero@infolink.com.br 
Integração (Integration) programmes; and the pedagogical proposal elaborated by the Landless Rural Workers' Movement - MST - and the material used in its rural camps and settlements; and the concept of totalities of knowledge in the books Palavras de trabalhador (Worker's word), published by the System of Adult and Youth Education of the Municipality of Porto Alegre, products of the educational experience with young and adult workers. It concludes exploring points that are common to all the studied teaching materials.

Key words: Adult and youth education. Teaching material.

\section{Para iniciar}

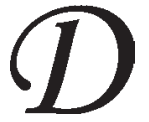

esde os primeiros tempos do Movimento de Educação de Base (MEB), no qual comecei minha vida profissional no período 1961-1966, interesso-me por material didático, tendo sido inclusive responsável pela produção e edição do Conjunto Didático Viver é lutar. O livro-texto que denomina esse conjunto, preparado para os recém-alfabetizados, foi publicado no final de 1963 e teve pequena parte de sua edição apreendida pela polícia de Carlos Lacerda, então governador do estado da Guanabara (antigo Distrito Federal, hoje município do Rio de Janeiro), em fevereiro de 1964, às vésperas do golpe militar. Pelo MEB ser ligado à Confederação Nacional dos Bispos do Brasil (CNBB) e pelo caráter explicitamente político-ideológico do livro, após sua apreensão ganhou enorme repercussão na imprensa e na televisão brasileiras, com acusações e críticas radicais. Por outro lado, teve reproduções em jornais e revistas, traduçóes em espanhol, francês e italiano e, posteriormente, uma versão radiofonizada em uma emissora católica do sul da Alemanha.

Para a produção desse conjunto, trabalhei com o material didático utilizado no Brasil nos anos de 1950, para a alfabetização e educação de base de adolescentes e adultos (na época não se usava a categoria jovem). Dispunha também da orientação de manuais da UNESCO e, claro, conhecia as críticas de Paulo Freire às cartilhas. No entanto, foi o pioneiro Livro de leitura para adultos, do Movimento de Cultura Popular do Recife (MCP), lançado em 1962, e Venceremos, a cartilha do movimento massivo de alfabetização de Cuba, iniciado logo após a revolução de 1959, que inspiraram uma nova linha de produção, principalmente de textos para os pós-alfabetizados. Por ocasião de minha tese de doutorado, no come- 
ço dos 1980, sistematizei o estudo desse material, inspirado nas análises feitas por Celso Beisiegel em seus dois livros: Estado e educação popular (São Paulo: Pioneira, 1974, recém-reeditado pela Líber Livros, de Brasília) e Política e educação popular (São Paulo: Ática, 1983). Essa sistematização foi traduzida no texto "Referências sobre materiais didáticos para a educação popular", publicado no livro Perspectivas e dilemas da educação popular, coordenado por Vanilda Paiva (Rio de Janeiro: Graal, 1984).

Recentemente, todo esse material didático e outros foram organizados no acervo do Núcleo de Estudos e Documentação sobre Educação de Jovens e Adultos da Universidade Federal Fluminense (NEDEJA/UfF) e continuei reunindo materiais produzidos após os anos de 1970, especialmente pela Cruzada ABC e pelo MOBRAL, até os dias atuais. Guardo também materiais relativos à alfabetização funcional em projetos de assentamento do INCRA e de extensão rural na zona do agreste de Pernambuco, sob o patrocínio da UNESCO. Da mesma forma que o Conjunto Didático Benedito e Jovelina, feito pelo MEB/Goiás na segunda metade dos anos de 1960 , esses materiais usados no meio rural foram influenciados pelo Sistema de Alfabetização de Paulo Freire, embora sem o conteúdo político explícito, essencial nas experiências do começo dos anos de 1960, mas inviáveis durante a ditadura militar.

Nos anos de 1980, foi retomada a produção de material didático para a educação de jovens e adultos comprometida com os movimentos sociais. Em 1982, a equipe de educação popular do Centro Ecumênico de Documentação e Informação (CEDI) - precursor da Ação Educativa -, coordenada por Sérgio Haddad, por solicitação do Centro de Documentação e Pesquisa da Amazônia, elaborou o Conjunto Didático Poronga, para alfabetização de homens e mulheres que viviam e trabalhavam no seringal Nazaré, município de Xapuri, no Acre, ação inserida no bojo de um projeto de desenvolvimento econômico, social e de educação popular. O trabalho foi feito com o Sindicato dos Seringueiros de Xapuri, encabeçado por Chico Mendes, e seu título refere-se à lamparina que os seringueiros da Amazônia usam na cabeça quando saem, na madrugada, para fazer extração do látex. O conjunto é composto de três cadernos: Português, contendo uma cartilha e exercícios complementares, Matemática e Orientações para o monitor. Em 1983, por solicitação do MEB de Caruari, em cujo território a ocupação principal era extração da bor- 
racha, foi feita uma adaptação do Poronga para o município de Japuri: Poronga - Edição Juruá.

Essa colaboração deu origem a outro conjunto para o Solimões, intitulado $O$ ribeirinho, também coordenado pela equipe de educação popular do CEDI e em colaboração com o MEB. Tem a mesma estrutura do Poronga: um volume para Alfabetização, outro para Matemática, ambos complementados pelos respectivos Cadernos do Monitor. Embora todos esses materiais se confessem tributários de Paulo Freire, a rigor, baseiamse apenas no levantamento vocabular previsto no sistema de alfabetização e nos temas geradores. No entanto, apresentam estrutura programática próxima do interessante Programa Didático Mutirão, preparado pelo MEB em 1965 e usado nas escolas radiofônicas. Observo, no entanto, que essas afirmações são provisórias, pois esses conjuntos didáticos ainda não estão convenientemente analisados. No acervo da Ação Educativa, encontra-se ainda uma coleção bastante diversificada de cartilhas e livros de leitura, produzidos no início dos anos de 1980 por centros educativos diversos, paróquias que mantinham grupos de educação popular, entre outros - material também que merece ser estudado.

Considero menos interessante voltar, nesse momento, à análise de materiais didáticos produzidos em décadas anteriores. Pretendo apresentar neste trabalho alguns materiais didáticos utilizados atualmente para a educação de jovens e adultos, produzidos por dois movimentos que se destacam no panorama nacional: Central Única dos Trabalhadores (CUT), Movimento dos Trabalhadores Rurais Sem-Terra (MST) e pelo Serviço de Educação de Jovens e Adultos, este último por ter conseguido implantar essa modalidade educativa no interior da Secretaria de Educação de Porto Alegre, fora dos moldes escolares tradicionais.

Esta opção justifica-se porque os respectivos materiais didáticos estão referidos a propostas político-pedagógicas inovadoras, que redefinem radicalmente a educação de jovens e adultos. Vale alertar, no entanto, que este trabalho não está completo: faltam dados sobre a abrangência dos programas e projetos em que foram ou estão sendo utilizados os materiais estudados, faltam avaliações sobre sua utilização, e algumas afirmações sobre os mesmos precisam ser comprovadas. Alerto, sobretudo, que não se pretendeu em momento algum avaliar os programas e seus respectivos materiais didáticos. Por outro lado, esta opção omite-se na apresentação e exame de outros materiais também interessantes, como 
os produzidos pelo Sapé - Serviços de Apoio à Pesquisa em Educação (Almanaque do Aluá n. 0 e 1); Vereda - Centro de Estudos em Educação (Material para alfabetização, com base em Paulo Freire, composto por cinco quadros, um bloco para o alfabetizador, cópia dos quadros para os alfabetizandos e lâminas dos mesmos para projeção; Almanaque Popular de Sabedoria n. 1 e 2 - Alfabetização: permanência e mudança, com texto de Vera Barreto e desenhos de Claudius Ceccon; Confabulando, seleção de fábulas por Vera Barreto e diagramação de Sebastiāo Xavier e Vera Barreto; Poetizando (Livro do educador), que ensina como trabalhar com poesia na alfabetização, com textos e comentários de Vera Barreto e Marisa Lajolo (quadrilha e cantiga); Historiando (Livro do educador), com textos de orientação, seleção e organização de histórias por Vera Barreto. Não considero também o novo material didático do MEB - Saber, viver e lutar, que apresenta reedições adaptadas e contextualizadas para os dias atuais do Conjunto Didático Viver e lutar, para uso no norte de Minas Gerais e em estados da região Nordeste. E existem outras experiências, com propostas político-pedagógicas específicas e materiais delas decorrentes, que ainda desconheço.

\section{CUT - Projeto político-pedagógico}

O projeto político-pedagógico da CUT para a educação de jovens e adultos trabalhadores é resultado da sistematização das reflexões feitas, no final dos anos de 1990, sobre educação profissional, com base nas experiências de educação integral dos trabalhadores.

As estratégias formativas da Central partem do desenvolvimento do homem como um ser integral, que se constitui mediante relaçôes sociais advindas do trabalho, assim como na relação com a natureza; relações que devem ser objeto de reflexão crítica, visando à libertação das condições de opressão e exclusão social, em particular proveniente de valores e atitudes de cunho discriminatório quanto às questões raciais, sexuais, religiosas, de gênero, dentre outras, concebendo a educação e a formação como direito do trabalhador. (CUT, 2001, p. 4)

Para concretizar essa proposta de formação, a CUT:

a) "toma como eixo fundamental o trabalho, compreendido como processo histórico de transformação da natureza e dos 
próprios homens, os quais, em sociedade, criam, por múltiplas formas de sociabilidade, os diferentes modos de produção e compreensão da existência”. Em segundo lugar, parte da "compreensão de que o conhecimento não pode ser concebido como algo externo e distante dos sujeitos, apartado das relações sociais que o constituem" (Rummert, 2004, p. 46; Bárbara, Miyashiro \& Garcia, 2004, p. 39);

b) considera a formação profissional como parte da educação integral, entendida como processo de autoformação continuada, que ocorre em todos os espaços sociais. Trata-se de criar um "processo de educação vinculado ao momento histórico, com a intenção de transformar o mundo e tornar o conhecimento constitutivo da própria vida" (CUT, Programa Integrar, módulo 12, Apresentação).

Os dois maiores programas por ela desenvolvidos, com base nas definições propostas, foram o Programa Integrar e o Programa Integração, que apresentarei a seguir, historiando-os e analisando os respectivos materiais didáticos.

\section{Programa Integrar}

Desenvolvido pela Confederação Nacional dos Metalúrgicos da CUT, a partir de 1995, com financiamento do Fundo de Amparo ao Trabalhador (FAT), do Ministério do Trabalho e Emprego, o Programa Integrar tinha por objetivo associar a formação para o trabalho com a formação geral e com a geração de alternativas de trabalho e renda.

Com base em sondagens feitas em São Paulo com trabalhadores desempregados ou em via de desemprego, que se ressentiam da falta de escolaridade, o Programa Integrar foi definido em parceria com a PUC/SP, assumindo uma concepção de educação que visava contribuir para a formação de um cidadão criativo, crítico, autônomo e com capacidade de intervir na sociedade. Sua proposta é bem fundamentada, como pode ser visto na sistematização constante da edição feita no Rio Grande do Sul:

O homem é concebido como um ser que se autoconstrói nas relações estabelecidas consigo mesmo, com a natureza e com suas semelhantes, nas condiçōes concretas do momento histórico vivido. 
O aluno trabalhador é concebido com um ser social que traz experiências de vida e conhecimento acumulados. Um sujeito fazedor de história que intervém na realidade e que se constrói nas ações coletivas. Um ser integral, cujas dimensões cognitivas, físicas, emocionais, econômicas, políticas, sociais, culturais, éticas e estéticas e espirituais interagem no processo de construção do conhecimento.

O conhecimento é concebido como fruto de um processo construtivo em que a aprendizagem dos sujeitos não está dada a priori e nem mesmo resulta do acúmulo de informaçóes vindas do meio exterior. Para aprender, o sujeito coloca em jogo suas hipóteses sobre a realidade, interage com o real e com os outros, reconstruindo estas hipóteses e avançando na compreensão desta realidade. Desta maneira, realiza-se um processo dialético de elaboração e reelaboração do conhecimento.

A educação é concebida como um processo internalizado pelo sujeito. Um processo que se constitui na relação direta com a dinâmica da sociedade, em que grupos e classes sociais agem e interagem dinamicamente em torno de interesses contraditórios. (Citolin, 1999, p. 24-25)

A revista Forma \& Conteúdo: a formação de Norte a Sul, publicada pela Secretaria de Formação da CUT em agosto de 2000, informava que o Programa Integrar estava sendo desenvolvido em 17 estados e 45 municípios, atingindo 250.000 mil trabalhadores, desdobrado em quatro subprogramas:

- Programa Integrar para Trabalhadores Desempregados (PID)

- Programa Integrar para Trabalhadores Empregados (PIE)

- Programa Integrar para Formação de Dirigentes (PIEF)

- Laboratório de Desenvolvimento Sustentável e Solidário (LDSS)

Para concretizar a proposta político-pedagógica da CUT, o Programa Integrar apresenta um currículo que, rompendo com a lógica disciplinar, objetiva propiciar aos educandos um processo formativo centrado "nas relações e inter-relaçôes com a vida dos trabalhadores jovens e adultos, partindo e dialogando com os conhecimentos trazidos por esses sujeitos para a reflexão sobre a realidade na qual estão inseridos" (Rummert, 2004, p. 145; Bárbara, Miyashiro \& Garcia, 2004, p. 35). Esse currículo desdobra-se em quatro módulos:

\section{Trabalho e Tecnologia}

Questão desencadeadora: Trabalho e relaçóes sociais 


\section{Matemática}

Questão desencadeadora: Os sujeitos se constroem e transformam a natureza

\section{Leitura e interpretação do desenho}

Questão desencadeadora: A cidade como espaço de intervenção do cidadão

\section{Gestão e planejamento}

Questão desencadeadora: Ação no mundo do trabalho e na sociedade

Cada módulo compreende um caderno para o aluno, com fotos, desenhos e leituras de motivação (contos, poesias, histórias etc.), além de exercícios e propostas de atividades, e outro para o professor, no qual é apresentado o plano de trabalho de diferentes matérias (no caderno de Matemática, encontra-se o plano dessa matéria e também de Ciências/ Português e assim por diante).

Essa organização dos chamados cursos regulares era complementada com outras ações: laboratórios pedagógicos, oficinas pedagógicas e formações de formadores. Nos cursos intervinham sistematicamente um professor e um instrutor, responsáveis por organizar o conhecimento no âmbito do ensino fundamental e da qualificação técnica. Articulados com os cursos, os laboratórios consistiam no desenvolvimento de atividades socioculturais, que permitissem conhecer o funcionamento de diferentes indústrias, órgãos públicos e entidades da sociedade civil, assim como de diferentes espaços da cidade que pudessem gerar alternativas de emprego e renda. Compreendiam também a participação em eventos culturais (teatro, exposições, música, dança, cinema), visando criar melhores condições de aprendizagem e contribuir para a formação da cidadania. As oficinas, realizadas em nível local ou regional, eram definidas como espaços de discussão de problemas sociais (por exemplo, o desemprego) e de estudo de formas de integração na sociedade. Compreendiam também cursos diversos para reforço de Matemática e Português ou domínio de novas técnicas (por exemplo, na Introdução à Informática eram trabalhados o editor de texto Word e o editor de planilhas Excel).

A formação dos formadores, por sua vez, era definida como um processo sistemático, centrado no aprofundamento de grandes temáticas e no desenvolvimento de metodologias de formação para o trabalho e de geração de emprego e renda. Foram elaborados roteiros específicos para 
cada módulo, tomando como ponto de partida a observação da realidade. Nessa ação, era trabalhada também a avaliação pedagógica, introduzindo critérios para as avaliações quantitativa e qualitativa e instrumentos pertinentes de registro e controle (CUT, 1999, não-paginado). ${ }^{1}$

A parceria inicial com a PUC/SP foi ampliada posteriormente com a COPPE/UFRJ, o UNITRABALHO e o DIEESE, para a produção dos módulos. O apoio financeiro do Fundo de Amparo ao Trabalhador (FAT) e o grande número de convênios assinados com diversas instituiçóes do campo econômico e do campo social permitiram a implantação do Programa Integrar em vários estados: São Paulo, Rio Grande do Sul, Rio de Janeiro, Santa Catarina, Pará, Paraná, Espírito Santo, Minas Gerais, Bahia. Dentro desses estados, desdobrou-se pelos municípios, viabilizando o atendimento a centenas de milhares de alunos. Acordos com escolas técnicas federais possibilitaram a certificação dos alunos concluintes do ensino fundamental e do ensino médio.

O material didático, na versão do Rio Grande Sul, é excelente e primorosamente impresso. No estado do Rio de Janeiro, foi preparada uma versão própria do Programa, sob o título Formação e requalificação para o trabalho. Organizado por disciplinas (Português, Matemática, Matemática Aplicada, Química, Física, Biologia, Geografia, Inglês e, ainda, Controle de Medidas, Reestruturação Produtiva, Leitura e Interpretação de Desenho etc.), não apresenta a mesma qualidade, nem mantém o mesmo caráter inovador do material do Rio Grande do Sul.

\section{Programa Integração}

Trata-se de um projeto nacional de qualificação profissional, ensino profissional e desenvolvimento sustentável solidário desenvolvido pelo Setor de Formação da CUT, com apoio financeiro do PLANFOR do Ministério do Trabalho e Emprego. ${ }^{2}$ Foi implementado no período de 2000 2002, sob responsabilidade direta da Secretaria Nacional de Formação, por meio de federaçóes e confederações de treze estados, atingindo treze ramos produtivos (Bárbara, Miyashiro \& Garcia, 2004, p. 30).

Seu objetivo era propiciar aos trabalhadores formação profissional e elevação da escolaridade em nível dos ensinos fundamental e médio. Para o atendimento dos trabalhadores no setor de telecomunicações, foram formadas, em onze estados, 120 turmas de ensino fundamental e 57 de ensi- 
no médio, cada turma com cerca de 30 alunos. A carga horária para o ensino fundamental foi fixada em 816 horas e para o ensino médio, em 1.030 horas (idem, ibid., p. 32).

O Programa Integrar apresentava uma estrutura curricular integrada, tendo como centro a reestruturação produtiva e articulando conteúdos técnicos e saber geral, organizados em quatro grandes áreas:

- Comunicação, cultura e sociedade

- Conhecimento e tecnologia

- Sujeito, natureza e desenvolvimento

- Gestão e alternativas de trabalho e renda.

Esse conjunto de temas, constante ao longo de todo o trabalho pedagógico, articula as várias disciplinas: Linguagem, Matemática, Ciências (Saúde e Biologia, História e Geografia). Os conteúdos, apresentados em doze módulos didáticos, deveriam ser trabalhados à medida que iam emergindo de um processo de reflexão e aprofundamento, que deveria combinar os conceitos e a experiência de vida do trabalhador.

1. Conhecimento e tecnologia I

2. Conhecimento e tecnologia II

3. Gestão e alternativas de trabalho e renda I

4. Comunicação, cultura e sociedade I

5. Comunicação, cultura e sociedade II

6. Gestão e alternativas de trabalho e renda II

7. Sujeito, natureza e desenvolvimento I

8. Sujeito, natureza e desenvolvimento II

9. Gestão e alternativas de trabalho e renda (ensino fundamental)

10. Conhecimento e tecnologia

11. Comunicação, cultura e sociedade III

12. Sujeito, natureza e desenvolvimento III

Cada módulo era constituído por:

a) Fichas para os alunos: coleção de textos geradores, escritos especialmente para o Programa, complementados por transcriçôes, 
poemas, desenhos e fotos. Os últimos módulos, principalmente o 12 , incorporam materiais produzidos pelos alunos de diferentes centros.

b) Apostila para os professores, apresentando os objetivos gerais relativos aos temas e conceitos a serem abordados e compreendendo roteiros diversos: subsídios bibliográficos, indicação de materiais necessários para explorar convenientemente as fichas para os alunos etc. Compreendem ainda objetivos específicos relativos a cada tema ou conceito, com sugestôes para sua abordagem, inclusive articulação de conhecimentos, propostas de pesquisa e recomendações aos professores. As sugestôes de procedimentos a serem trabalhados pelos alunos compreendiam orientação para a leitura individual e grupal, fichamento de textos, elaboração de quadros-síntese, interpretação de gráficos e imagens; orientação para o trabalho em pequenos grupos e discussão no coletivo; sistematização dessas discussões, elaboração de gráficos, desenhos, murais etc.

c) Previa-se que os conteúdos fossem trabalhados apenas por um professor ou por uma dupla de professores (de educação e de formação profissional). Além do treinamento específico para a atuação pedagógico-didática, foram preparados também Cadernos de orientação metodológica e uma Coletânea de textos/subsidios para o educador.

Em minha opinião, o Programa Integração apresenta a proposta teórico-metodológica mais inovadora e o material didático mais interessante. Apesar dos problemas corridos em sua aplicação - em particular, decorrentes do ainda pouco aprofundamento teórico-prático da interdisciplinaridade e a dificuldade dos professores assumirem a abordagem de várias disciplinas, em função de sua própria formação básica e experiência profissional anterior -, deve ser objeto de maiores estudos e de outras pesquisas, como a realizada por Sonia Rummert, da qual derivou o artigo citado.

MST - Programa de educação de jovens e adultos

Não é preciso historiar o Movimento dos Trabalhadores SemTerra, nem mesmo ressaltar a atenção dedica à educação das crianças e 
dos jovens e adultos, assim como dos dirigentes e militantes em geral. No MST, a luta pela educação acompanha a luta pela terra; o compromisso do movimento pela educação está organicamente ligado à reconstrução da sociedade brasileira. Desde sua criação, em 1984, mas sobretudo nos anos de 1990, promoveu uma seqüência de eventos: seminários e encontros nacionais de educadores para a reforma agrária, dentre eles, encontros nacionais e regionais de educadores de jovens e adultos. Ao mesmo tempo, apoiado por convênios e em pareceria com instituições de ensino, criava os cursos de Magistério (normal de nível médio) e realizava cursos de preparação de monitores para alfabetização em projetos de assentamento - uma das primeiras necessidades que se impunham. Em 1998, o apoio do Ministério do Desenvolvimento Rural, através do Instituto Nacional de Colonização e Reforma Agrária (INCRA), possibilitou a criação do Programa Nacional de Educação na Reforma Agrária (PRONERA), viabilizando a implantação de ações educativas apoiadas pelo governo federal e realizadas em parceria com universidades e movimentos sociais. A experiência mais conhecida do PRONERA é a Pedagogia da Terra, já com várias turmas diplomadas e atualmente com cursos em diversas universidades.

Ao mesmo tempo em que ganhava terreno e apoio para estender e diversificar suas ações, o MST, progressivamente, ampliava sua compreensão de alfabetização e seu desdobramento em direção ao ensino fundamental, como direito dos jovens e adultos não-escolarizados, assim como aprimorava a compreensão relativa à educação. Em paralelo aos eventos, cuidava da elaboração e da publicação de textos normativos sobre educação, sobre educação de jovens e adultos e sobre a relação da educação com o projeto político do movimento.

O próprio MST, no Caderno de Educação n. 11 - Educação de Jovens e Adultos: sempre é tempo de aprender (MST, 2004) - apresenta uma síntese dos momentos mais significativos da luta pela terra e, paralelamente, faz um balanço da caminhada na conceituação da ação educativa. No mesmo caderno, apresenta essa conceituação nos seguintes termos:

\section{A. Convicções fundamentais}

- Todas as pessoas têm direito de aprender

- Todas as pessoas têm direito à escolarização

- Sem-terra tem o dever de se alfabetizar 
- Sempre é tempo de aprender

- Todas as pessoas têm saberes e saberes diferentes

- A alfabetização faz parte da educação popular do campo

- A educação está vinculada à formação

- A educação de jovens e adultos é maior que a alfabetização e não precisa acontecer só na escola

- Cada sociedade tem suas linguagens de sociabilidade

- Somos educadores e educadoras do povo

\section{B. Princípios metodológicos}

- Respeitar o jeito de aprender de cada tempo da vida

- Partir da necessidade: a pessoa se interessa em aprender quando necessita

- Educar as pessoas para se apropriar da história e se tornar sujeitos

- Relacionar os processos de educação de jovens e adultos com os processos de formação do MST

- Conhecer os sujeitos em sua realidade e a realidade social onde estão inseridos

- Trabalhar com vivências geradoras

- Consolidar condutas e posturas e diversificar didáticas

- Organizar o ambiente alfabetizador

- Produzir um ambiente educativo

\section{Elementos gerais de pedagogia}

- Educação do movimento popular e não para o movimento popular

- A mística como elemento de formação humana

- Sem emoção não há aprendizado

- Não se aprende fora da cultura

- Conhecimento novo não se constrói sem um engate num conhecimento anterior

D. Elementos operacionais 
- Organizar as turmas levando em conta a socialização e a heterogeneidade entre os educandos

- Organizar internamente as turmas

- Fazer diagnóstico permanente

- Garantir o planejamento das atividades

- Registrar o processo educativo

- Fazer uma avaliação permanente

- Garantir a formação permanente das educadoras e dos educadores

- Ter método de acompanhamento do processo educativo

É bastante grande o número de publicações do MST, editadas pelo Coletivo Nacional de Educação e pelo Instituto Técnico de Capacitação e Pesquisa em Reforma Agrária (ITERRA), em diferentes séries de cadernos. ${ }^{3}$ Boa parte do material publicado destina-se aos formadores e vários textos relativos à educação dizem respeito a escolas de ensino fundamental para crianças, embora algumas diretrizes contemplem também a educação de jovens e adultos. Os textos mais importantes estão reunidos nos Cadernos de Educação, dos quais estão disponíveis os seguintes números:

2. Alfabetização (de crianças)

3. Alfabetização de jovens e adultos: como organizar

4. Alfabetização de Jovens e Adultos: didática da linguagem

5. Alfabetização de Jovens e Adultos: educação matemática

6. Como fazer a escola que queremos: o planejamento

8. Princípios da Educação do MST

9. Como fazemos a escola de educação fundamental

11. Sempre é tempo de aprender (histórico das experiências, dos encontros e da produção dos textos)

Seguindo a mesma orientação dos Cadernos de Educação, encontramos disponíveis:

1) Formação de educadoras e educadores: o planejamento na alfabetização de jovens e adultos, que na primeira parte explora os fundamentos teórico-metodológicos da alfabetização; e, na segunda, apresenta experiências de planejamento a partir de temas 
geradores: assentamento, produção, a falta de participação e a compreensão do processo de luta pela terra, exclusão, migração, valor da beleza e histórias de vida.

2) Desafios da formação, instrumento de estudo e debate sobre o tema "formação de quadros", resultado da Reunião do Coletivo de Formação realizada em 2002, abordando explicitamente a formação política e sua relação com a educação.

A segunda série que pode ser destacada é a dos Cadernos do ITERRA:

1. ITERRA: memória cronológica

2. Instituto de Educação Josué de Castro: projeto pedagógico

4. Movimento dos Trabalhadores Rurais Sem-Terra: levantamento bibliográfico

5. Instituto de Educação Josué de Castro: reflexões sobre a prática

6. Pedagogia da terra

8. Alternativa de escolarização dos adolescentes em assentamentos e acampamentos do MST (14 a 17 anos)

O MST tem outras publicações, agrupadas em séries ou não, destinadas a todos os militantes ou especificamente às mulheres, todas com expresso conteúdo educativo e organizacional:

Cadernos de Formação

30. Gênese e desenvolvimento do MST - Bernardo Mançano Fernandes

34. O MST e a cultura - Ademar Bogo (Caderno de Formação n. 34)

35. Método de organização: construindo de um novo jeito (idem, n. 35)

\section{Cadernos de Saúde}

1. Lutar por saúde é lutar pela vida

2. Programa Terra e Saúde

\section{Caderno do Educando}

Pra soletrar a liberdade n. 1 - Nossos valores 
Pra soletrar a liberdade n.2 - Somos sem terra

Caderno de Cooperação Agrícola

10. O que levar em conta para a organização do assentamento

Publicaçôes do Coletivo Nacional de Mulheres

Mulher sem terra

Mutirão: nenhuma trabalhadora rural sem documento

Compreender e construir: novas relaçôes de gênero (coletânea de textos)

\section{Coleção Fazendo História}

3. A história de uma luta de todos (para crianças)

7. A história do menino que lia o mundo - Carlos Rodrigues Brandão (idem), 5a edição em julho de 2003, com 20.000 exemplares.

\section{Sem Série}

- Paulo Freire, um educador do povo (para adultos): textos, depoimento, carta e fala de P. Freire para os sem-terra; textos de Frei Betto, Miguel Arroyo, Moacir Gadotti, Mário Cabral, Miguel González e Ana Maria Freire.

- Nosso jeito de cantar (livro de canções populares da terra)

- Como construir com terra (Escola Nacional Florestan Fernandes)

\section{SEJA/MOVA de Porto Alegre - Palavra de Trabalhador}

O Sistema de Educação de Jovens e Adultos (SEJA), da Secretaria Municipal de Porto Alegre, é inovador na forma de superar a transposição, na maior parte das vezes mecânica, de conteúdos e procedimentos usados no ensino regular de crianças para as escolas de jovens e adultos. Considerando que também a adaptação dos programas tradicionais do ensino fundamental não tem dado respostas convincentes às necessidades apresentadas pelos que iniciam tardiamente sua escolarização ou retornam à escola, não raro depois de tentativas mal sucedidas, trabalhando na perspectiva da interdisciplinaridade, o SEJA elaborou para a 
educação de jovens e adultos um currículo estruturado em totalidades do conhecimento, que se efetiva em abordagens significativas para os educandos, a partir de suas experiências de vida.

Para o SEJA, as totalidades do conhecimento “(...) constituem os instrumentos conceituais a partir dos quais a interdisciplinaridade poderá efetivar-se na dependência da atitude, da predisposição, dos conceitos epistemológicos dos professores, em particular do grupo que formam e reformam (...)" (Secretaria Municipal de Educação, 1999, p. 31).

São seis as totalidades de conhecimento:

1. Construção dos códigos escritos (exemplo: alfabético-numérico)

2. Construção dos registros dos códigos

3. Construção das sistematizações dos códigos

4. Aprofundamento das sistematizações

5. Generalizações dos códigos

6. Transversalidades entre códigos, trabalhando com conceitos que envolvem as relações homem/mulher/natureza.

As três totalidades iniciais correspondem ao processo de alfabetização, ou seja, aos primeiros quatro anos do ensino fundamental. As turmas, com uma média de 25 alunos, são atendidas por um professor e cada totalidade tem a duração de 400 horas/aula, divididas em dois trimestres. A partir dos conhecimentos que o aluno traz, trabalha-se a construção do código escrito, levando em consideração o fato de a leitura de mundo ser indissociável da leitura da palavra. $\mathrm{O}$ conceito de alfabetização é permeado pelas transformações da sociedade contemporânea, de forma que a inserção no mundo da leitura e da escrita permita a utilização dessas habilidades na resolução dos problemas cotidianos.

As três totalidades finais abrangem conteúdos das oito disciplinas do currículo dos últimos anos do ensino fundamental: Língua Portuguesa, Matemática, História, Geografia, Ciências Físicas e Biológicas, Língua Estrangeira (Francês, Inglês, Espanhol, Educação Física e Educação Artística). Há um professor para cada disciplina e a carga horária é idêntica para todas elas (duas horas semanais). No entanto, em conseqüência da Resolução n. 06/86 do CFE, respaldada pela Resolução n. 213/94, é reforçado o número de horas-aula de Português e Matemática, por meio do ensino a distância (Secretaria Municipal de Educação, 1966, p. 31- 
32). Nessas totalidades, são aprofundados os conceitos desenvolvidos nas três totalidades iniciais, a partir dos componentes curriculares específicos de cada área do conhecimento. Dessa forma, os conteúdos abordados ganham maior abrangência e complexidade.

Afirma-se que os diferentes espaços educativos de SEJA/MOVA ressignificam as totalidades de conhecimento em um movimento de participação, no qual os atores envolvidos no processo são protagonistas do trabalho pedagógico.

Faz parte do currículo a formação permanente dos educadores envolvidos no processo, que se efetiva em diferentes instâncias gerais, específicas dos grupos, por projetos, por regiōes da cidade, por identidades de áreas, de alfabetização e outras.

$\mathrm{Na}$ realização de suas atividades, o SEJA articula-se com outras secretarias e diversos departamentos da Prefeitura Municipal, visando atender a heterogeneidade do universo de jovens e adultos, inclusive aqueles portadores de necessidades especiais; articular a escolarização com a formação específica de funcionários públicos; atender à escolarização de internos em hospitais psiquiátricos, quando possível; articular a escolarização aos esforços de educação profissional, qualificação e requalificação de trabalhadores, geração de trabalho e renda.

O SEJA publica anualmente um "caderno" chamado Palavra de Trabalhador, documentando as produções textuais e gráficas dos jovens e adultos das diferentes turmas. De 1991 a 2003 foram publicados 12 "cadernos", sendo que, a partir de 1998, também passaram a ser inseridas produções dos alunos do MOVA. ${ }^{4}$

Embora não possa (nem deva) ser considerado um "livro didático", as turmas do SEJA dispõem de exemplares do Palavra de Trabalhador, sendo muitas vezes utilizados em sala de aula para leitura, análise de textos e base para discussóes. ${ }^{5}$ Alguns professores testemunham que os "cadernos" produzem um certo encantamento, tanto naqueles que escreveram e vêm seus textos impressos em um livro, como nos que se encontram nas histórias do lugar ou se identificam no testemunho de companheiros.

O Palavra do Trabalhador, ao mesmo tempo em que significa valorização da produção dos jovens e adultos e valorização dos próprios jovens e adultos, é também material para divulgação da experiência realizada pelo SEJA e pelo MOVA. Por sua vez, os "cadernos" permitem, para um analista, visualizar como se desenvolve o processo educativo, quais são e 
porque são escolhidos os temas geradores e como são trabalhados. O cuidado de contextualizar a produção permite entender sua motivação desencadeadora. O registro das várias fases do processo mostra, por exemplo, o texto em sua forma inicial, ainda tosca; sintetiza as reflexões sobre o mesmo, em termos de aprofundamento e aperfeiçoamento; e apresenta-o reformulado, agora em termos da linguagem considerada correta.

A própria seqüência dos "cadernos" é significativa, como se poder ver na síntese apresentada a seguir. Os "cadernos" mostram que a experiência de trabalhar com as totalidades de conhecimento vai amadurecendo e é bastante significativo que um dos últimos "cadernos" publicados tenha sido produzido pelos próprios alunos.

n. 1/1991: Amostragem das diferentes fases do processo de alfabetização; espaço de expressão para os jovens e adultos em processo de alfabetização.

n. 2/1993: A produção dos alunos é introduzida por um texto teórico-metodológico de duas professoras: Contribuição para uma política educacional de trabalho com a produção textual de jovens e adultos. Exemplos de texto inicial/reflexões sobre o texto/texto reformulado.

n. 3/1994: Registro, para um mesmo tema, de produçôes elaboradas nas totalidades iniciais ( 1 a 3 ) e complementares ( 4 a 6$) .1^{\text {a }}$ Totalidade: Contextualização - conceito de cidade. $1^{a}$ Proposta: Representação gráfica da cidade. 2a Proposta: Texto sobre Porto Alegre, nossa cidade, nossa história. Segue propondo outras contextualizações (por exemplo: Meu país etc.)

n. 4/1995: Mesma estrutura do anterior, partindo de uma contextualização inicial sobre beleza, seguida de uso das drogas etc.

n. 5/1996: Textos, desenhos, fotomontagens produzidos nas diversas totalidades, organizados em capítulos. Exemplos: A matemática em nossas vidas; Biologia: nosso corpo etc.

n. 6/1997: Idem, novamente organizados por totalidades.

n. 7/1998: Abordagem: movimentos populares: seu conteúdo e suas propostas de ação. Motivação: Orçamento participativo de Porto Alegre. 
n. 8/1999: Explicação do processo metodológico do SEJA/MOVA: "O ponto de partida da ação dos professores(as) e alunos(as) foi um estudo da realidade através de uma pesquisa de caráter sócio-antropológico, realizada nas comunidades onde os(as) alunos(as) estão inseridos(as)." (...) "O trabalho pedagógico caminha na direção dos temas geradores, oportunizando aos alunos(as) uma melhor compreensão da sua realidade, objetivando o aluno reconhecer-se como sujeito participante do processo histórico, contribuindo também para o resgate de sua auto-estima."(...) "Como vocês podem ver na produção textual dos alunos(as) do SEJA, a capacidade de fazer reflexôes sobre o cotidiano está presente quando retratam temas como saúde, habitação, educação, meio ambiente, cidadania, participação coletiva (orçamento participativo), etnias, identidade (histórias de vida - resgates), relações, sociedade, emoções, imaginação, símbolos, medos e perspectivas (adolescência e terceira idade), trabalho feminino e infantil, lutas populares, problemas sociais, desemprego, violência, transformação, qualidade de vida, liberdade etc." (p. 9-10).

n. 9/2000: Caderno temático, com a apresentação feita pelos alunos. Motivação: Brasil 500 anos - uma releitura crítica da história. Registra: "O trabalho deste coletivo [SEJA/MOVA] parte da realidade e do saber popular para dialogar com o saber científico, contribuindo assim para o conhecimento de forma crítica e transformadora." (p. 7).

n. 10/2001: Apresentação feita em conjunto pelos professores, educadores e educandos do SEJA e do MOVA, que registram: "Muitas são as temáticas abordadas, debatidas, estudadas, aprofundadas, questionadas e analisadas no cotidiano das turmas. A busca do conhecimento se dá respeitando os diferentes tempos de aprendizagem, resgatando a auto-estima, num espaço no qual todos aprendem e todos ensinam, numa relação dialógica.” (p. 7). Segue uma apresentação da Coordenação de Educação de Jovens e Adultos: "As dez publicações do Palavra de Trabalhador nos remetem para a densidade das reflexões sobre o significado de publicar produções que traduzem as andanças de alunos jovens e adultos em processo de alfabetização e de escolarização em nível fundamental através de seus próprios textos. A leitura desses textos evidencia o quanto os fatos escolhidos para serem narrados são encharcados de significados." (...) "Partilhando seus sentimentos, fantasias, medos e desejos, os alunos do SEjA, do MOVA e do Projeto de Educação dos Trabalhadores em Resí- 
duos Sólidos Recicláveis, nesta $10^{a}$ edição do Palavra de Trabalhador, nos apresentam descobertas e concepçôes de um contexto mais amplo, que ultrapassa os limites da sala de aula, ou de temas específicos trabalhados no cotidiano escolar. Nesta publicação somos brindados com textos abordando as relaçôes humanas, família, violência, histórias de vida e de trabalho, reflexões sobre política e sociedade, a história de Porto Alegre e do meio ambiente, as reflexões sobre escola, aprendizagem e educação, contemplando também seus sonhos, utopias, histórias e poesias." (p. 11).

n. 11/2002: "Palavra de Trabalhador, em 2002, apresenta um pouco do muito que é realizado cotidianamente nos diferentes espaços em que SEJA e MOVA acontecem. Sua apresentação, por regiôes da cidade, valoriza as identidades singulares e plurais existentes na diversidade de projetos político-pedagógicos, que são permanentemente qualificados na interação desses professores-educadores com o conjunto de espaços educativos dessa cidade que pretende ser cada vez mais educadora." (p. 15).

n. 12/2003: A apresentação é feita por alunos do SEJA e do MOVA que afirmam: "O livro quer mostrar a todos não só o que os professores ensinam, mas também o que os alunos podem ensinar. Mostra que no SEJA e no MOVA há uma troca de saberes; os alunos trazem suas histórias, suas experiências, que vão dar novos significados aos conhecimentos trazidos pelos livros. Partindo de acontecimentos atuais, buscam desvendar o passado com um olhar crítico, o que as pessoas sentem, o que elas pensam.” (p. 7).

Pontos comuns aos programas educativos e materiais didáticos examinados

1. Destacam-se, em primeiro lugar, as propostas político-pedagógicas claramente expressas pela CUT e pelo MST, assim como pelo SEJA/MOVA de Porto Alegre. Essas propostas são fruto de elaborações coletivas, amadurecidas durante anos. Mesmo quando definidas inicialmente com apoio de assessorias ou por uma instância central, tornam-se produto de ampla discussão coletiva, com base na experiência realizada e em criteriosa avaliação dos resultados. Em especial, compreendem objetivos e estratégias bem definidas, que orientam a ação educativa e balizam a produção do material didático. 
2. Assumem um conceito específico de educação integral, que compreende a educação geral e a formação profissional (no caso da CUT), ou definem a educação em sentido amplo, como preparação para a vida coletiva e a transformação da sociedade (no caso do MST), ou ainda como retomada da situação atual dos educandos para uma nova vida na cidade (no caso do SEJA/MOVA). Explícita ou implicitamente, defendem a educação dos jovens e adultos como um direito.

3. É ponto comum a valorização dos conhecimentos dominados pelos jovens e adultos, derivada de processos de escolarização anteriores, abandonados ou interrompidos e, sobretudo, pela aprendizagem da experiência (saberes de experiências feitos, como dizia Paulo Freire), tomados como pontos de partida. A superação dos conhecimentos já dominados e a apropriação de novos conhecimentos são feitas sempre numa perspectiva crítica, procurando perceber cada fato particular na totalidade global e no momento histórico em que foi ou está sendo construído. Os educandos são considerados sujeitos na produção desses conhecimentos e é garantida a participação de todos na produção de novos conhecimentos, assim como na disseminação dos mesmos.

4. Todas as propostas advogam a superação da estrutura curricular por disciplinas, própria dos sistemas escolares, e ensaiam trabalhar na perspectiva interdisciplinar. Essa postura é traduzida no material didático; no entanto, as avaliaçōes disponíveis indicam a dificuldade de ser assumida pelos educadores, por conta de sua formação inicial fortemente referida a disciplinas, pela formação insuficiente para assumirem essa nova perspectiva e pelas próprias condições de trabalho. O SEJA/MOVA, talvez por estar compreendido no sistema educacional e por ter tido maior continuidade, indica ter ido mais longe nessa experimentação, o que tem enorme valor para a garantia do direito à educação de jovens e adultos, defendido atualmente por todos os que trabalham com essa modalidade de ensino.

5. É forte o investimento na formação dos formadores para a ação educativa, via de regra, com uma referência explícita ao projeto político assumido pelo movimento ou pela instituição, tendo em vista sua atuação com competência técnica e compromisso político. No caso do MST, significa também a consolidação do compromisso político com o movimento.

6. É também forte a referência, implícita ou explícita, à pedagogia de Paulo Freire, orientando a proposta político-pedagógica, balizando a definição dos princípios e estratégias e, sobretudo, justificando a pos- 
tura de partir da experiência dos educandos, valorizando-a e discutindoa para que seja superado o senso-comum, numa atitude de diálogo construtivo.

7. Na mesma perspectiva, desenvolvem outro conceito de avaliação, às vezes definida como avaliação emancipatória, não raro com base na autoavaliação. Os resultados da ação educativa são entendidos como auto-estima pessoal, ajuda mútua e preparação para ao trabalho e para a vida.

Recebido em outubro de 2006 e aprovado em março de 2007.

\section{Notas}

1. Não foram localizadas informações sobre a realização e a avaliação das ações de formação.

2. Segundo Rummert (2004, p. 138), "A sigla PLANFOR refere-se, indistintamente nos documentos oficiais, tanto a Programa Nacional de Formação Profissional quanto a Plano Nacional de Formação Profissional. O PLANFor foi instituído pela resolução n. 126/96, do Conselho Deliberativo do Fundo de Amparo ao Trabalhador (CODEFAT), está subordinado ao Ministério do Trabalho e Emprego e opera com recursos do Fundo de Amparo ao Trabalhador".

3. A educação do MST é seguramente o tema que dispóe de maior número de estudos realizados sobre ele, inclusive em teses e dissertaçōes, e o maior número de livros a ele dedicados, entre eles o pioneiro Pedagogia do Movimento Sem Terra: escola é mais que escola, de Roseli Salete Caldart (1999).

4. Em 2004 foi publicado o $13^{\circ}$ Palavra do Trabalhador, em quatro volumes, um para cada região da cidade.

5. Em anos anteriores, chegaram a ser distribuídos a todos os alunos.

\section{Referências bibliográficas}

BÁRBARA, M.M.; MIYASHIRO, R.; GARCIA, S.R.O. Experiência de educação integral da CUT: políticas em construção. Rio de Janeiro: DP\&A, 2004.

CALDART, R.S. Pedagogia do Movimento Sem Terra: escola é mais que escola. Petrópolis: Vozes, 1999.

CENTRAL ÚNICA DOS TRABALHADORES (CUT). Programa Integrar: introdução aos módulos. São Paulo: CUT; Confederação Nacional dos Metalúrgicos, 1999. 
CENTRAL ÚNICA DOS TRABALHADORES (CUT). Bases do projeto político-pedagógico do Programa de Educação Profissional da CUT-Brasil. São Paulo: CUT; Secretariado de Formação Profissional, 2001. (Educação e trabalho, n. 1)

CITOLIN, S. (Org.). Programa Integrar RS: proposta político-pedagógica; caderno de reflexão. São Paulo: cuT; Confederação Nacional dos Metalúrgicos, 1999.

MOVIMENTO DOS TRABALHADORES RURAIS SEM TETO (MST). Educação de jovens e adultos: sempre é tempo de aprender. São Paulo: MST, 2004. (Caderno de Educação, n. 11).

PORTO ALEGRE. Secretaria Municipal de Educação. Em busca da unidade perdida: totalidades de conhecimento. Porto Alegre: Secretaria Municipal de Educação, 1996. (Caderno pedagógico, n. 8).

PORTO ALEGRE. Secretaria Municipal de Educação. Totalidades do conhecimento: em busca da unidade perdida; um currículo de educação popular. Porto Alegre: Secretaria Municipal de Educação, 1999.

RUMMERT, S. Programa Integração: avanços e contradições de uma proposta formulada pelos trabalhadores. Revista Brasileira de Educação, Belo Horizonte, n. 27, p. 138-153, set./dez. 2004. 